\title{
Negócios de comida e trajetórias de imigrantes brasileiros no Oeste da Austrália: adaptação de receitas, jornada dupla e muita determinação.
}

\section{Food business and trajectories of Brazilian immigrants in Western Australia: adaptation of recipes, double shift and a lot of determination.}

\section{Renata Utchitel Casado \\ Lecturer in the Management and Organisations department at the University of Western Australia - UWA Business School. email: renata.casado@uwa.edu.au}

\section{Eduardo Picanço Cruz}

Professor Associado III do Departamento de Empreendedorismo e Gestão da Universidade Federal Fluminense. email:epicanco@id.uff.br

\section{Roberto Pessoa de Queiroz Falcão}

Professor do Mestrado em Administração (PPGA-Unigranrio) e Professor visitante de empreendedorismo na Universidade Tecnológico de Monterey (México). email:robertopqfalcao@gmail.com

\section{RESUMO}

O artigo se propõe a investigar, por meio da análise de trajetórias de sete empreendedores imigrantes brasileiros no Oeste da Austrália, como se deu o processo empreendedor de negócios de comida. Por meio de entrevistas em profundidade e análise documental, os autores oferecem subsídios sobre os recentes fluxos de brasileiros para o Oeste da Austrália, um fenômeno recente e pouco coberto pela literatura acadêmica em português. Ademais, o mesmo também contribui para a literatura do empreendedorismo étnico e imigrante, dado que o contexto brasileiro é menos pesquisado do que o dos imigrantes asiáticos na Austrália. Os resultados particularmente enfocam aspectos da criação e desenvolvimento de negócios do setor alimentício, que se valem da alavancagem étnica, embora sofrendo barreiras no que tocante à sua configuração, e necessidade de adaptação ao público local.

Palavras-Chave: effectuation, empreendedores imigrantes, negócios de comida, Austrália.

\section{ABSTRACT}

The article aims to investigate, through the analysis of trajectories of seven Brazilian immigrant entrepreneurs in Western Australia, how the entrepreneurial process of food business took place. Through in-depth interviews and documentary analysis, the authors offer insights into the recent flows of Brazilians to Western Australia, a recent phenomenon and little covered by academic literature in Portuguese. Furthermore, it also contributes to the literature on ethnic and immigrant entrepreneurship, given that the Brazilian context is less researched than that of Asian immigrants in Australia. The results particularly focus on aspects of the creation and development of businesses in the food sector, which use ethnic leverage, although suffering barriers in terms of their configuration, and the need to adapt to the local public.

Key-words: effectuation, immigrant entrepreneurs, food businesses, Australia. 


\section{INTRODUÇÃO}

O presente artigo busca evidenciar casos de negócios de comida, criados por imigrantes brasileiros no Oeste da Austrália. Os negócios, além de sua função objetiva de geração de lucro aos empreendedores, também trazem uma sensação de pertencimento às comunidades étnicas. Alimentos possuem valores simbólicos e culturais, resgatando o senso de comunidade de imigrantes, como visto em lojas de especialidades culinárias e restaurantes tradicionais dos enclaves étnicos, assim como sendo ponto central das festividades típicas de imigrantes (por exemplo em EVERTS, 2010; DAHINDEN, 2012).

Os negócios étnicos e imigrantes tem sido incluídos nos debates recentes sobre imigração (RAMADANI, BEXHETI, DANA, RATTEN, 2019; WANG, HII, 2019; BOUDREAUX, 2020), o qual gravita entre dois polos: um lado que defende políticas mais rígidas sobre a imigração, inflando a discriminação étnica nas sociedades desenvolvidas (caso dos EUA e de alguns países europeus), e o outro lado que defende o incentivo às políticas migratórias buscando-se atrair mão-de-obra qualificada (caso do Canadá e Austrália, por exemplo). É fato que bilhões de dólares circulam em enclaves étnicos e em negócios criados por imigrantes, sejam eles negócios do ramo de alimentação ou startups e empresas globais nascidas fundadas por imigrantes (DANA, VIRTANEN, BARNER-RASMUSSEN, 2019). As redes transnacionais de comércio, bem como as redes locais de varejo étnico, são estabelecidas em escalas regionais, dentro da diversidade das regiões metropolitanas dos cinco continentes. Fluxos de ideias, mentes, capital e bens ocorrem diariamente, promovidos por comunicações e meios de transporte rápidos e baratos (DRORI, HONIG, WRIGHT, 2009). Ao mesmo tempo que os empreendedores imigrantes se concentram no mercado local gerando riqueza e empregos, introduzem novos hábitos alimentares, fornecendo comidas exóticas para os habitantes locais ou promovendo a perpetuação de receitas de "comida caseira" para seus colegas de trabalho ou das comunidades imigrantes do exterior (HONIG, 2018), o que muitas vezes é realizado de maneira effectual (SARASVATHY, 2009), sem um planejamento formal por parte dos imigrantes.
A migração brasileira para a Austrália é um fenômeno relativamente recente, mas o número de brasileiros na Austrália vem dobrando a cada cinco anos desde 2000, como mostra o último censo (AUSTRALIAN BUREAU OF STATISTICS [ABS], 2016). Na última década, a migração do Brasil teve a segunda taxa de crescimento mais rápida na Austrália, depois do Nepal e à frente do Paquistão e da Índia (DEPARTAMENTO DE ASSUNTOS INTERNOS [DHA], 2018). O Brasil é um dos principais parceiros comerciais da Austrália na América Latina. Além disso, é um dos principais países que envia estudantes para a Austrália (COMISSÃO AUSTRALIANA DE COMÉRCIO E INVESTIMENTO [AUSTRADE], 2019). Na Austrália Ocidental, onde essa pesquisa foi realizada, o número de brasileiros aumentou $460 \%$ entre 2001 e 2011, de 380 para 1.758, surgindo com eles novos negócios étnicos (CLARKE, 2016).

O objetivo do artigo é o de contribuir para a compreensão do processo empreendedor de imigrantes que estabelecem negócios de comida, ao se analisar sete casos de empreendedores imigrantes brasileiros no Oeste da Austrália. O estudo foi conduzido na região por meio da análise de entrevistas em profundidade, contrastando com a literatura existente a respeito do empreendedorismo de imigrantes que estabelecem negócios de comida em todo o mundo. Para explorar as trajetórias empreendedoras dos brasileiros em sua comunidade étnica no Oeste da Austrália, este estudo se baseia na abordagem teórica da effectuation (SARASVATHY, 2009), na qual os negócios são criados por meio de recursos disponíveis, sejam oriundos do background cultural do empreendedor, de suas experiências prévias ou das circunstâncias da vida de imigrante. Dessa maneira, as questões de pesquisa que nortearam este estudo foram:

1) quais seriam as características comuns a suas trajetórias empreendedoras?

2) quais seriam os fatores geradores de alavancagens étnicas nos negócios de empreendedores imigrantes brasileiros estabelecidos na Austrália Ocidental?

As contribuições deste estudo são duplas. Primeiro, o artigo oferece insights sobre os recentes 
fluxos de brasileiros para o Oeste da Austrália, fenômeno recente e a literatura e pouco coberto pela literatura acadêmica em português (FIRMEZA, 2007; MARGOLIS, 2013). Segundo, o mesmo também contribui para a literatura do empreendedorismo étnico e imigrante, particularmente ao enfocar os aspectos da criação e desenvolvimento de negócios do setor alimentício que se valem da alavancagem étnica embora sofrendo barreiras no que tocante à sua configuração (CECCARELLI, 2019). Outrossim, o empreendedorismo de imigrantes é um campo pouco pesquisado na Austrália (RAMETSE et al., 2018), sendo que as pesquisas, até agora, concentraram-se principalmente nas comunidades de migrantes asiáticos (AZMAT, FUJIMOTO, 2016; COLLINS, 2003; COLLINS, LOW, 2010; LEVER-TRACY, IP, 2005).

\section{ETNIA COMO RECURSO DE ALAVANCAGEM PARA EMPRESAS}

A etnia pode ser atribuída como um fator de discriminação ou alternativamente como fator de alavancagem para empreendedores imigrantes. Os concorrentes locais do setor de alimentos podem vislumbrar empreendedores de comida étnica como aquelas barraquinhas de comida exótica ou food-trucks presentes em diversas metrópoles, sendo atribuídos a esses negócios baixa qualidade sanitária, inadequação aos gostos locais e, eventualmente, aspectos de ilegalidade (por exemplo em WAHLBECK, 2007; MARTIN, 2014; GUDMUNDSSON, 2013).

Ademais, o elemento cultural étnico pode ser visto pelos amantes de comida exótica como uma experiência sensorial e cultural interessante. Para clientes daquela etnia esses negócios de comida podem ser encarados como promotores de uma sensação de um lugar em que 'alguém pode se sentir em casa’ (DION, SITZ, RÉMY, 2011).

Já em uma abordagem culturalista, diversos trabalhos seminais apontaram para orientação empresarial derivada de contextos culturais de grupos étnicos específicos (por exemplo, BASU, 1998; SRINIVASAN, 1995; WERBNER, 1990). Os críticos (por exemplo, BARRETt et al., 1996, RAM, 1997; RAM et al., 2000) diziam que a cultura por si só não poderia explicar inteiramente o processo empreendedor. Outros autores enfatizavam o quadro mais amplo de passivos imigrantes ou étnicos como fatores cruciais para o trabalho independente (ou do auto-emprego), devido à falta de oportunidades e discriminação no mercado de trabalho (ANTHIAS 1992; Jones et al. 1993; RATH, KLOOSTERMAN, 2000). Além disso, ao analisar o uso de recursos étnicos, de acordo com Aldrich e Waldinger (1990), condições e oportunidades de mercado também devem ser levadas em consideração. A incorporação mista (mixed embeddedness theory), por exemplo, reconhece o contexto complexo de fatores situacionais, culturais e institucionais que moldam os empreendimentos étnicos (por exemplo, KLOOSTERMAN, RATH, 2001; RATH, 2000; KLOOSTERMAN, RATH, 2018). O capital social, envolvendo laços sociais, também é citado por alguns autores como mecanismos para obter fontes de financiamento, informações para montar e gerir negócios, além de contratar e manter trabalhadores com relações de confiança e reciprocidade (por exemplo, BONACICH, MODELL, 1980; LIGHT, 1984; GRANOVETTER, 1985; LIGHT, BONACICH, 1988; PORTES, 1998; WILSON, PORTES, 1980).

No entanto, o auto emprego é uma das principais ferramentas dos imigrantes de combate à exclusão que frequentemente enfrentam no mercado de trabalho, fazendo com que os imigrantes sejam mais independentes por conta própria do que as populações nativas (REZAEI, 2007). Além disso, é bastante frequente que os imigrantes encontrem nichos específicos no setor de alimentos: o açaí, brigadeiros e o pão-de-queijo no caso Brasileiro, certos tipos de sanduíches como kebabs e schwarmas, no caso dos árabes, cortes e preparados especiais de carne como o Mongolian Grill ou churrasco rodízio brasileiro, pratos picantes - como o mexicano, comida Thai ou indiano Tandoor, dentre outros exemplos.

O negócio de alimentos para os imigrantes pode ser visto de duas maneiras: (i) como uma "economia cinzenta", onde os imigrantes ilegais se estabelecem como vendedores ambulantes, às vezes não respeitando os regulamentos de saúde e segurança, onde o empreendedor contrata membros de sua família ou de sua rede de relações como mão-de-obra barata; ou como (ii) negócios incorporados a um "ethos imigrante", ligados ao orgulho nacional ou ao exemplo 
de esforço e iniciativa de empreendedores (ver GIBSON, OGBU, 1991; LAUGLO, 1999). Adicionalmente não se pode descartar a questão da identificação da oportunidade de vender produtos exóticos ao público local (CRUZ, FALCÃO, MANCEBO, 2019).

\section{EMPREENDEDORISMO DE ALIMENTOS ÉTNICOS}

Segundo Ray (2011), desde o início do Censo dos Estados Unidos da América, em 1850, quando foram identificadas ocupações e local de nascimento, os dados mostram uma forte correlação entre as ocupações de serviços de alimentação e os novos grupos de imigrantes. Ao analisar os números da cidade de Nova York, por exemplo, o autor argumenta que nascidos no exterior ocuparam a maioria dos empregos (como empregados domésticos, funcionários de hotéis e restaurantes, donos de hotéis, barmen, comerciantes de mantimentos, padarias e açougues), atingindo a cifra de $60 \%$ de algumas dessas ocupações.

Na década de 1920, milhões de americanos já haviam se familiarizado com pratos chineses americanos como chop suey e chow mein (CHOI, 2016). No entanto, levar o Oriente para a parte central da América exigiria uma negociação cuidadosa do orientalismo americano, que teria que distanciar simultaneamente a comida chinesa da estranheza e da mesquinhez de Chinatown, mantendo seu apelo exótico.

A fim de ilustrar várias questões sobre empresas de alimentos étnicos, foram selecionados alguns trabalhos da literatura internacional para apresentar evidências dos mecanismos de criação de negócios de alimentos étnicos, suas relações com os imigrantes e a população local. Anthias e Cederberg (2009), por exemplo, consideram importantes as dimensões do capital social, sobretudo o papel dos vínculos étnicos. Os autores exploram o uso da etnia na busca de uma melhor posição social e econômica, analisando três grupos étnicos minoritários no setor de alimentos no Reino Unido. Os autores argumentam que o uso de vínculos étnicos pelas minorias é multidimensional e contextual. Às vezes, eles o usam para ajudar os atores a lidar com a marginalidade, e outras vezes para fornecer maneiras de compensar as desvanta- gens estruturais do mercado. Suas narrativas foram extraídas do componente britânico do projeto de pesquisa 'Etnogeneração: as chances de vida da segunda geração em famílias de empreendedores étnicos', um estudo internacional financiado pela União Europeia envolvendo equipes no Reino Unido, Alemanha, França, Dinamarca e Grécia (APITZSCH et al., 2006). O estudo também explora processos de qualidade de vida, com foco em questões de gênero e intergeracionais que ocorrem nos negócios de alimentos de minorias étnicas.

Já Wahlbeck (2007) examina o negócio de kebab de empreendedores imigrantes turcos estabelecidos na Finlândia. O autor descreve um caminho regular de imigrantes da Turquia que acabam frequentemente como trabalhadores independentes ou empregados no setor de fast-food ou de restaurantes na Finlândia. Dado que o mercado de trabalho finlandês é severamente regulamentado e fechado para imigrantes, os funcionários turcos trabalham sob condições adversas em lojas de kebab, esperando que um dia possam abrir seus próprios negócios. Martin (2014), por outro lado, explora a questão de diferentes regulamentações para diferentes tipos de empreendimentos, conduzindo um estudo em Chicago. Enquanto os empreendedores de "food-trucks gourmets" conseguem superar regulamentações alimentares rigorosas por meio de um discurso criativo, as barracas de comida mexicanas são marginalizadas pelas autoridades públicas.

Reconhecendo que o empreendedorismo é um campo de pesquisa já bem estabelecido, com suas próprias abordagens teóricas (SHANE, 2012), a abordagem de efectuation ajudaria na compreensão do comportamento empreendedor que os imigrantes desenvolvem nos países anfitriões, sobretudo no ramo alimentício.

Sarasvathy (2009) desenvolveu essa abordagem empreendedora alternativa por meio de experimentos com empreendedores especializados em determinados ramos, sobretudo nos da alimentação. A abordagem mais tradicional ao empreendedorismo, que ela chama de causation é contrastada com uma mais adequada sob níveis mais altos de incerteza, que ela chama de efectuation. Na abordagem de causation, o empreendedor descobre uma oportunidade de mercado analisando o mercado, encontrando 
lacunas entre oferta e demanda e procurando tendências de compra dos consumidores realizando a "exploração deliberada de oportunidades" (FISHER, 2012, p.1.023), sendo a atividade de planejamento é, portanto, crucial para o processo de causalidade, assim como as informações no mercado aguardando para serem exploradas. Já na abordagem efectuation, considera-se a natureza imprevisível e ambígua do ambiente, bem como a falta de informações disponíveis para o empreendedor tomar suas decisões. Fisher (2012) resume os principais fatores que explicam o comportamento empreendedor por meio da efectuation: (i) o foco nas médias em vez de nas metas predeterminadas; (ii) mentalidade de perda acessível em vez de retorno esperado ao decidir sobre opções viáveis; (iii) basear-se no capital social e na cooperação, em oposição à análise dos concorrentes; e (iv) explorar e não evitar contingências (Fisher, 2012, p. 1.024). Seria, portanto, o controle do empreendedor sobre o conjunto de meios disponíveis, que podem ser a experiência, habilidades e redes sociais anteriores (Fisher, 2012). No nível individual, esses meios representam grande parte do capital humano, financeiro e social ao qual o empresário possui ou tem acesso.

\section{METODOLOGIA}

Esta é uma pesquisa qualitativa, no qual foram selecionados sete casos (relativos aos empreendedores do setor alimentício) um total de 21 entrevistas em profundidade realizadas com empresários brasileiros, entre março e novembro de 2019 em Perth, Oeste da Austrália. Segundo Morse (1994), quando se utiliza o método de entrevistas em profundidade, o número de participantes pode ser de no mínimo seis. A seleção de casos ricos e ilustrativos de empreendedores brasileiros do ramo alimentício foi capaz de evidenciar circunstâncias ou características de importância para o assunto sob investigação (RITCHIE, LEWIS, NICHOLLS, ORMSTON, 2014). Portanto, os participantes foram convidados e selecionados de acordo com as características desejadas, sendo elas: (i) empreendedores brasileiros que dividissem herança cultural comum brasileira, e cujos negócios estivessem intrinsecamente entrelaçados em estruturas sociais de origem brasileira em seu país de origem (ALDRICH,
WALDINGER, 1990); (ii) indivíduos proprietários de empresas formais, do ramo alimentício, com alguma identidade ou envolvimento na comunidade - excluindo todas as empresas que operassem na informalidade, ou serviços não registrados para fins fiscais (WILLIAMS, 2009).

Um questionário semiestruturado permitiu ao entrevistador padronizar as perguntas sem influenciar as opções de resposta dos participantes, possibilitando aos entrevistados a formulação de respostas pessoais que melhor expressassem sua subjetividade (DENZIN, LINCOLN, 2011). As entrevistas também fizeram parte de um projeto que estuda o empreendedorismo brasileiro em diferentes países. $\mathrm{O}$ roteiro de entrevistas possuía quatro seções, destinadas a explorar: (i) as experiências migratórias dos participantes; (ii) sua qualificação, emprego e empreendedorismo antes e depois da saída do Brasil; (iii) sua experiência no processo de abertura da empresa no país de destino; e (iv) informações relacionadas ao marketing e a estratégia dos negócios. As entrevistas duraram entre 50 e 90 minutos e foram realizadas em português. Trechos transcritos gravados durante as entrevistas foram analisados e agrupados em categorias de análise (CRESWELL, 2009), um processo auxiliado pelo software NVivo12 e informado pela revisão de literatura (DENZIN, LINCOLN, 2011). A capacidade do NVivo de classificar, combinar e vincular conceitos permitiu a exploração adequada dos dados sem a perda do contexto (BAZELEY, JACKSON, 2013). O tempo total das 21 entrevistas originais somou $16 \mathrm{~h} 29$ minutos. O relatório de análise extraído do NVivo gerou um total de 66 páginas, com 15 categorias de análise.

Para definição das categorias a serem exploradas no presente texto foi realizado, inicialmente, o processo de organização, composta de quatro sub-etapas: i) uma primeira leitura dos textos transcritos (leitura flutuante) das entrevistas; ii) escolha dos trechos mais significativos das entrevistas fazendo uma demarcação do que seria analisado; iii) formulação de hipóteses anteriores derivadas das entrevistas; iv) referenciamento de índices e elaboração de indicadores, através do recorte de passagens nos textos analisados (BARDIN, 2006). Uma segunda fase consistiu em explorar o material com a definição de categorias (características comuns à suas trajetórias 
empreendedoras), que de fato foram influenciadas pelo roteiro semiestruturado das entrevistas, pois havia questões específicas a serem investigadas no roteiro. A exploração do material foi uma etapa crucial, pois possibilitou uma riqueza de interpretação e inferências sobre os assuntos tratados (BARDIN, 2006). Já na terceira fase, onde ocorreu o tratamento dos resultados, inferência e interpretação, uma análise reflexiva e crítica foi realizada nos relatos das entrevistas (BARDIN, 2006).

\section{CARACTERÍSTICAS COMUNS E TRAJETÓRIAS EMPREENDEDORAS}

\subsection{Apresentação dos negócios analisados}

Uma descrição das principais características dos negócios e dos empreendedores é apresentado na tabela 1. Destaca-se que todos chegaram na Austrália com visto de estudante.

Tabela 1: Descrição dos empreendedores e empresas entrevistadas

\begin{tabular}{c|c|c|c}
\hline Número da Entrevista & Tipo de Negócio & Tempo no país & $\begin{array}{c}\text { Idade do Negócio } \\
\text { (base 2019) }\end{array}$ \\
\hline 3 (mulher) & Quentinhas brasileiras & 8 anos & 2 anos \\
\hline 6 (mulher) & Restaurante e Bar & 12 anos & 4 anos \\
\hline 12 (homem) & Restaurante & 15 anos & 3 anos \\
\hline 15 (mulher) & Food -Truck, Café & 11 anos & 3 anos \\
\hline 17 (mulher) & Padaria e confeitaria vegana & 1 ano & 6 anos \\
\hline 18 (mulher) & Brigadeiros (confeitaria) & 11 anos & 10 anos \\
\hline 21 (homem) & Pão de queijo (fábrica) & & \\
\hline
\end{tabular}

Fonte: elaboração própria

Algumas características comuns foram observadas durante as entrevistas e contatos com os empreendedores. Todos vieram com visto de estudante, $\mathrm{e}$ percebendo o crescimento da comunidade brasileira, pensaram em criar negócios do setor de alimentação. As dificuldades vieram, em sua grande maioria, decorrentes da falta de planejamento e do entendimento sobre as implicações de se ter um negócio, incluindo a falta de capital de giro. Outra dificuldade inicial vivenciada pelos empreendedores foi a necessidade de dupla jornada, sendo que a maioria manteve outros empregos até o negócio efetivamente decolar. De forma geral todos os negócios começaram voltados ao público brasileiro. No entanto, dado o baixo giro de compras de brasileiros e o preço final caro para os imigrantes em sua maioria com status de estudantes, gerou uma necessidade de adaptação de suas receitas ao paladar local.
Complementando as informações da tabela 1, apresenta-se a tabela 2 , a seguir, contendo um breve histórico de cada empresa.

O planejamento incipiente e effectual (SARASVATHY, 2009) foram vistos como elementos frequentes nos negócios de alimentação pesquisados. Além disso, a presença da dupla jornada (na fase inicial do negócio) e da entrada no país com visto de estudante, corrobora as trajetórias imigrantes descritas por Wahlbeck (2007) e Martin (2014). As categorias mais frequentes (e relacionadas com a questão de pesquisa 1), que emergiram dos discursos transcritos das sete entrevistas, selecionadas e codificadas no software NVivo, são apresentadas a seguir. 
Tabela 2: Histórico das empresas

\begin{tabular}{|c|c|}
\hline Empresa & Histórico \\
\hline 3 & $\begin{array}{l}\text { A proprietária saiu do país há oito anos decepcionada com o país e com os brasileiros. Juntou dinheiro para vir à Austrália estudar } \\
\text { inglês, deixando marido e filho no Brasil, separando-se de seu marido logo em seguida, quando também seu filho decidiu morar } \\
\text { no país. Trabalhou inicialmente em uma agência de intercâmbio, começando a fazer coxinha de maneira informal (inicialmente } \\
\text { nem sabia fazer mas pegou a receita com a ex-sogra) para pagar suas despesas com o filho, entregando-as prioritariamente para } \\
\text { um restaurante brasileiro. Um dia sugeriu à dona do restaurante fazer uma feijoada, improvisou, preparou e foi um sucesso. Cada } \\
\text { novo prato sugerido, olhava no Youtube ou perguntava para a mãe (no Brasil) como fazer. Começou a fazer brigadeiro, beijinho, } \\
\text { esfirrinha, coxinha, surgindo assim a empresa. }\end{array}$ \\
\hline 6 & $\begin{array}{l}\text { Restaurante brasileiro e catering de salgadinhos. Casal iniciou o negócio há quatro anos com catering de salgados, abrindo um } \\
\text { ano depois uma pequena lanchonete. Há cerca de três anos abriram um bar/restaurante com conceito de "boteco" e "quiosque de } \\
\text { beira de praia" brasileiro em um dos bairros mais turísticos da cidade. }\end{array}$ \\
\hline 12 & $\begin{array}{l}\text { O entrevistado chegou com visto de estudante indo trabalhar em uma pizzaria e logo na primeira semana percebeu que queria } \\
\text { abrir um restaurante na Austrália. Trabalhou muito e abriu um restaurante de comida italiana que hoje é gerenciado por um italia- } \\
\text { no. Agora se dedica ao seu segundo negócio, uma churrascaria com identidade nacional brasileira voltada ao público. }\end{array}$ \\
\hline 15 & $\begin{array}{l}\text { A proprietária chegou com visto de estudante, convencendo seu noivo (atual marido) a ir para a Austrália. Trabalharam muito e } \\
\text { abriram um food truck. Depois compraram um café. }\end{array}$ \\
\hline 17 & $\begin{array}{l}\text { Confeiteira de bolos e doces veganos e gluten free que começou o negócio há aproximadamente três anos. Fez curso de chefe } \\
\text { na Austrália em } 2011 \text {. Cansada de seu emprego, fez uma viagem para Bali e no seu retorno decidiu trocar de emprego, testando } \\
\text { umas receitas desse tipo de comida em casa. Fez um curso de raw dessert lá em Bali e arrumou um emprego numa loja orgânica } \\
\text { da Austrália. Iniciou seu negócio com uma loja online com a ajuda do marido que era web designer, para depois começar a } \\
\text { vender em feiras, mercados de final de semana e cafés, além de estúdios de yoga também, frequentados por esse público. }\end{array}$ \\
\hline 18 & $\begin{array}{l}\text { A entrevistada começou a fazer e vender brigadeiros no Brasil, em uma faculdade do ABC, onde também recebia encomendas, } \\
\text { mas depois se especializou como chocolatier. }\end{array}$ \\
\hline 21 & $\begin{array}{l}\text { Uma das maiores histórias de sucesso da comunidade brasileira. O casal começou o negócio há cerca de } 10 \text { anos vendendo pão } \\
\text { de queijo congelado. Eles apostaram na tendência do gluten-free e hoje têm o produto disponível em três das quatro grandes } \\
\text { redes de supermercado da Austrália, cobrindo as principais cidades do país, sendo que o produto não tem diversificação - apenas } \\
\text { um tipo de pão de queijo tradicional. }\end{array}$ \\
\hline
\end{tabular}

Fonte: elaboração própria

\subsection{Motivações para empreender}

\section{Inicialmente os empreendedores relatam mo-} tivações para empreender, relacionadas a questões financeiras, mas também citam elementos relacionais ou sociais. Quer seja pela motivação de trazer seu filho para morar na Austrália:

Meu filho chegou aqui na Austrália e decidiu ficar. Foi assim que surgiu o Rio 40, foi por causa do meu filho, eu falo, "a culpa é sua”, por que para fazer um dinheiro extra e pagar o visto, que eu tinha de ser tipo um "sponsor" (patrocinador) dele [...] Só o visto custava $\$ 4.000$, mais escola [...] era $\$ 11.000$. [entrevista 3]

Ou pela busca de liberdade, independência financeira ou estilo de vida mais flexível:

Queríamos sair do Brasil. Desde que nos conhecemos já era nosso sonho sair do país para fazer um intercâmbio. [entrevista 18]
Então, a gente começou a ver áreas em poderíamos ter uma vida diferente do que estávamos levando, com emprego, você não consegue chegar aonde você quer $[. .$.$] a gente sempre teve$ ambições maiores [...] ter liberdade pra viajar, independência financeira [...] Daí pensei em abrir a empresa de catering, pois acredito que aqui estava bem limitado mesmo em termos de opções. [entrevista 6]

Tinha o objetivo de, um dia, ter um negócio funcionando sem eu precisar estar presente. Gerar um lucro para eu poder, depois de algum tempo, parar de estar aqui de madrugada fazendo as coisas funcionarem. [...] $\mathrm{O}$ restaurante italiano agora está com um italiano que toca pra mim. Eu treinei ele [...] eu vou ainda uma vez por semana, levo as coisas, fecho tudo, o caixa [...] [entrevista 12]

Abri o negócio por dois motivos: Realização -porque quando você vê que tá crescendo, que as pessoas gostam, dá aquele ânimo de novo de fazer, e segundo, pela flexibilidade de eu poder trabalhar em casa e eu fazer o meu horário [...] conciliar, e mesmo antes do Dylan (bebê) eu conseguia [...] não tenho aquela "prisão" de ficar trabalhando de segunda a sexta num lugar e sei lá [entrevista 17] 
O empreendimento pode ter sido um sonho antigo, pensado e trabalhado para sua concretização, mas galgado no relacionamento e sintonia dos sócios, aliado à sua competência profissional:

Trabalhamos muito, só que a gente sempre quis abrir um negócio, sempre teve esse sonho, desde que a gente (estava) na faculdade, porque a gente é muito bom junto [...] meio que um casamento, até no trabalho, porque o que ele faz e o que eu faço se casam. Eu sou boa com pessoas e sei me organizar ele é um excelente chefe de cozinha. Mas a gente focou primeiro na residência, depois na nossa cidadania. Depois começamos a fazer catering pros amigos [...] Teve uma festa de fim de ano dessa empresa, que o cara recebeu, todos os diretores do mundo. A gente cobrou super barato pra época [...] até hoje ele é nosso cliente, [...] depois disso veio, a festa junina, as coisas começaram a aparecer. [entrevista 15]

\subsection{Visto de entrada e Trajetórias comuns}

Os empreendedores também relataram que chegaram ao país inicialmente com visto de estudante, sendo frequentemente para aprender inglês. Em geral vieram acompanhados de seu cônjuge (ou companheiro), ou mesmo iniciando relacionamento ao chegar no país, conforme relatos:

Eu vim com o meu marido, Thiago, que na época era meu namorado. A gente veio [...] com o visto de estudante [...] decidiu vir pra Austrália porque ele já trabalhava com TI no Brasil e é uma área que exige muito o Inglês. Então, todos os empregos grandes e bons que ele aplicou, ele reprovou na parte de Inglês. Então, a gente veio [...] para aprender Inglês e [...] ter emprego na área dele. [entrevista 6]

Quando cheguei, falei, "Vou ficar aqui no máximo um ano", depois um ano mais pra aprender o inglês [...] depois volto para poder fazer a minha empresa do Brasil fluir. Vendi minha casa própria pra vir pra cá. Cheguei na Austrália e logo depois, a escola que eu estava fazendo inglês faliu. Perdi tudo! [...] renovei um segundo visto com ajuda da minha mãe, ela conseguiu um empréstimo, e ela vendeu seu carro no Brasil. Foi nesse processo que conheci meu marido. Depois de três ou quatro dias a gente decidiu morar juntos, [...] que aqui é muito normal isso. [entrevista 3]

Eu cheguei em março 2004. Eu vim com visto de estudante. Sou biólogo formado. Sempre quis sair do país para aprender outra língua. Tinha um primo que tinha vindo para a Austrália, em Sydney. [...] mas vim para o oeste da Austrália por não ter muito brasileiro, assim poderia aprender inglês. [entrevista 12]

Eu terminei a faculdade de hotelaria, meu marido fez gastronomia [...] ele já estava com um emprego legal em São Paulo e eu não falava inglês. Aí a gente decidiu que eu vinha fazer um intercâmbio, só de seis meses. Chegando aqui eu conheci uma brasileira, que trabalhava em uma agência de emprego. Eu não tinha um bom inglês. Daí ela viu a aliança na mão e [...] falei que meu noivo (na época, hoje marido) era chefe no Brasil. Daí ela [...] perguntou se ele não pensava em vir para a Austrália (mas) [..] falei não, que estávamos focados em ir para a Europa porque lá é o coração da gastronomia. Então ela [..] começou a me explicar sobre as empresas de catering, quanto ganhavam, [..] ele veio como estudante, mais ficou um mês só porque chegando aqui ele já tinha um emprego. E foi assim, a nossa vida mudou da água pro vinho ali, aí a gente decidiu que ia ficar na Austrália. [entrevista 15]

Meu marido era meu namorado na época [...] Queríamos sair do Brasil, (para) [.. ] Canadá, Irlanda, aquela mesma história de sempre, né? Ou pra cá. Mas como tínhamos dois amigos morando há 8 meses aqui em Perth [...] viemos com visto de estudante. [...] (éramos) formados em inglês no Brasil, mas quando chegamos vimos que não éramos fluentes [...] Meu marido (web designer) tinha um emprego bom no Brasil. Antes de sairmos mandou currículos pra cá. Em um mês aqui ele arrumou empregou em uma empresa de design. Aí, através desse emprego dele, ele conseguiu o visto de permanência. Eu fiquei estudando inglês. Meu visto saiu depois, também através de empregos aqui. [entrevista 17]

Queríamos sair do Brasil. Desde que nos conhecemos já era nosso sonho sair do país para fazer um intercâmbio. [entrevista 18]

Por que a Austrália? Porque primeiro eu estava procurando um país pra aprender inglês, viemos com visto de estudante os dois, e by the way com $\$ 1000$ no bolso. E também porque a gente gosta de praia, eu sou surfista, então por isso. Então, inglês, o surf, as praias e o clima. No Brasil eu tinha acabado de me formar em administração de empresas esperando terminar o curso pra pra vir. [...] eu trabalhava na área de contabilidade de uma empresa, foi meu último emprego no Brasil. [entrevista 21]

\subsection{Falta de planejamento e entendimento sobre "ter um negócio"}

Após trabalharem em outros empregos, com o tempo de permanência no país, os empreendedores perceberam o crescimento da comunidade brasileira, vislumbrando oportunidade emergentes em negócios de comida. A falta de um planejamento formal (ou planejamento incipiente) denota o aspecto effectual (SARASVATHY, 2009) dos negócios imigrantes, conforme explicitado a seguir.

Decidi formalizar meu negócio porque me denunciaram, e isso me deixou "P" da vida. [...] estava grávida, de licença maternidade na empresa, e comecei a fazer "business plan", mas eu 
não tinha 1 dólar no bolso. Foram três meses, quase quatro de licença maternidade fazendo o "business plan". Ofereci para algumas pessoas. Chegou um estudante e falou assim: "olha, meu pai tem a grana". Ele ficou comigo uns quatro meses. Estava indo super bem, só que [...] os dois despreparados, ele na parte financeira (o marido) e eu aprendendo a cozinhar. $\mathrm{Na}$ primeira vez que usei um fogão industrial, queimei 50 litros de feijoada, teve que jogar fora. [...] Fui aprendendo na raça”. Mas eu tinha meu business plan, [...] eu comecei a buscar consultoria profissional, com chefes, com pessoas da parte de negócios [...] a gente viu muitos erros. Hoje se eu abrisse um restaurante naquele local, eu ia saber o que fazer. Mas naquele momento eu não estava preparada pra isso. A gente começou com 6 funcionários, todos brasileiros e todos despreparados, tão mais despreparados que eu, absurdamente [...] Era amigo de amigos, ninguém sabia fazer nada. [entrevista 3]

Um ano antes de eu sair do meu emprego que a gente começou a desenvolver o business plan [...] a pesquisar o mercado. Começamos com o serviço de catering para depois abrirmos o restaurante. [...] Só que nosso dinheiro era muito limitado. Também não tínhamos experiência de mercado. [...] ainda está sendo difícil, mas naquela época [...] aluguel caríssimo, funcionários, etc. Na época a gente não tinha nem estrutura financeira nem de administração [...]. A gente não sabia que um simples outdoor na frente do restaurante faria uma diferença tão grande como fez. Fiz um business plan porque trabalhei no Governo e lá eu [...] [entrevista 6]

Financeiramente foi difícil. Bem difícil. Quando eu abri aqui, fisicamente, eu fiz tudo. Tive dificuldade com o "council" de aprovar o projeto. Tem umas leis que tem sentindo; tem outras leis que não tem sentido nenhum. Eu fiquei trabalhando dois anos até de madrugada no vermelho pra fazer o 'italiano' ir pra frente, e, o que for necessário para fazer pra cá, vou fazer igual. [entrevista 12]

A gente não tinha muito dinheiro pra investir, então pensamos, o food truck é um investimento de mais ou menos de 70 a 80 mil contando com os equipamentos é toda a carcaça, as licenças e tal [...] era o dinheiro do cash flow que a gente não podia gastar, mas arriscamos mesmo assim. Tivemos muitas dificuldades, passamos muito no vermelho, quase perdemos nossa casa. Escolhemos o cara errado para construir nosso food truck [...] muito enrolado [...] ele não terminava o serviço. Quando o food truck ficou pronto, tivemos dificuldade para explicar o que é uma tapioca para o australiano. Depois do sucesso do food truck precisávamos ajustar o calendário de eventos anuais [...] foi quando começou a surgir a ideia de montar um café. Coincidentemente um conhecido estava vendendo o restaurante. Ele e a esposa decidiram ir embora pra Portugal. Falamos com ele que queríamos alguma coisa para funcionar de segunda a sexta, daí ele decidiu vender. Mudamos bastante coisa no café, coloquei essas coisinhas brasileiras, coloquei bolo de fubá, de cenoura, o pessoal ama, tô vendendo bem. [entrevista 15]

Acabei fazendo um curso e percebi que eu tenho que ser mais constante em relação a publicidade e eu tenho que aparecer mais, porque o pessoal não quer só ver bolo, o pessoal quer ver você. Quando eu comecei o business, eu achava que ia ser a mulherada da academia, da yoga, a mulherada healthy, mas pelo contrário, o meu público são os mais senhores que têm alergia ao glúten ou ao ovo ou que não querem comer açúcar [...] de 50 pra cima ou as menininhas veganas de 14 a 21 . Esse é o meu maior público [...] a mãe me manda e-mail falando: "Olha, minha filha vai fazer (anos), ela quer um bolo igual ao [...] que ela viu [...]no Instagram”. Na época que eu fazia as feiras de final de semana perdi muito produto, pois não sabia quantas pessoas iria atender. [...] Meu marido falou: "Chega dessa vida”, porque ele também me ajudava, né? Ele ia comigo. Ele estava trabalhando 7 dias na semana [...] às vezes eram dois markets por dia, era sábado de manhã e sábado à tarde, sexta à noite, domingo. E aí ele falou [...] vende só pelo online. [entrevista 17]

Quando nós chegamos já tínhamos pesquisado previamente no Brasil, como fazia pra abrir um negócio, trouxemos nossa panelinha que chegou 15 dias depois, e não pudemos começar a produção sem a licença específica pra exercer a atividade, e ela demorou quatro meses pra sair, e nesse período também teve aquele receio de começar, me perguntando pra quem eu iria oferecer e como eu iria fazer, até que uma menina que trabalha com festas, a Rose, me mandou uma mensagem, me parece que alguém tinha me indicado pra ela, e ela me perguntou se eu trabalhava com doces e eu confirmei, e levei uma caixinha com os doces pra ela, e eu coloquei tanta energia naquela caixinha que ela adorou, disse que era o melhor que ela já tinha comido! Então nós começamos a trabalhar juntas em festas e fui prospectando clientes, e hoje graças a Deus [...] estamos crescendo e atualmente eu tenho encomendas pra lotar a minha semana [...] consigo pagar minhas contas, lógico que eu ainda faço extras. [entrevista 18]

\section{No caso do negócio 21, o fato do empreendedor} vir de uma família também empreendedora e de ter formação em administração o ajudou no quesito planejamento, conforme relato:

Minha mãe tem 12 irmãos e os 13 são empreendedores [...]A gente foi (ao) órgão do governo aqui, Small Business Center [...] como se fosse um Sebrae (e) [...] eles nos deram um manual pra você fazer um business plan de 70 páginas. E fizemos [...] Como nós dois, a Yuri é formada em turismo e eu em administração, [...] já tínhamos noção que tínhamos que fazer um planejamento desde o day 1. [...] fomos seguindo e a cada ano fazíamos a revisão das nossas metas, das direções e íamos ajustando esse business plan, (mas) [...] demorou sete anos pra gente atingir o break even, [...] sabíamos exatamente onde nós estávamos pisando [...] nós dois somos super hard working, então esse é um ingrediente pro business dar certo. Além do sonho, você tem que ter muita determinação, porque se você não tiver você vai desistir no primeiro obstáculo [...] todo dia tem problemas que nós temos que superar. [...] 0 único risco que nós tínhamos era realmente não saber se nós íamos continuar na Austrália, porque nós não tínhamos o visto. Então foi arriscado, porque nós fizemos um "super- investimento". A gente coloca muito nas mãos de Deus... [...] talvez a idade seja um ponto importante, porque não tínhamos filhos na época, e talvez hoje em dia com filhos e uma idade 
mais avançada... você acaba ficando mais receoso em relação a riscos. [entrevista 21]

\subsection{Dupla jornada.}

\section{A dupla jornada de trabalho parece também ser} uma constante na constituição dos negócios imigrantes brasileiros.

Fazia em casa mesmo e levava em casa. Então as vezes a feijoada, as coisas já estavam cortada, a couve pronta, sabe, só pra fazer lá de forma rápida, pq como eu trabalhava na empresa de intercâmbio, eu tinha até as 9 da manhã pra fazer essa feijoada, deixar lá na quarta-feira e ir pra empresa de intercâmbio, era meio que dois "Jobs". [entrevista 3]

Mas eu continuei trabalhando. Depois que eu abri o meu business, mesmo porque eu não conseguiria financeiramente. Não vim de uma família rica que pudesse bancar o meu business. Então de pouquinho em pouquinho, a gente teve que construir o dinheiro para ter o investimento. No início, eu chegava do meu emprego às $18 \mathrm{~h}$ da tarde, tomava banho e fazia salgadinhos até umas $4 \mathrm{~h}$ da manhã e acordava às $6 \mathrm{~h}$. Por 6 meses eu fiz isso e várias vezes eu quis desistir. Várias mesmo. Era muito difícil e principalmente pelo fato de que você estar cansada, estressada. E [...] sono acho que deixa a você muito limitado. Então foi uma época BEM difícil que afetou várias áreas da minha vida. [entrevista 6]

A gente tinha os nossos full times Jobs e fazíamos o catering como um leque porque a gente não tinha dinheiro para investir em qualquer coisa, porque tudo pra investir custa e custa muito, ainda mais na área de alimentação. [entrevista 15]

Jornada de empresária com a maternidade: Mas, é difícil, porque ao mesmo tempo [...] tem o lado da maternidade, que aí tem aquela pressão: "Nossa, tô deixando o meu bebê". Tudo bem, vai três vezes na semana, é bom pra ele, porque a gente tá sozinho aqui, não tem família pra ele interagir [...] aquele cansaço, né? [...]focar no business, focar na casa. Meu marido falou: "Chega dessa vida", porque ele também me ajudava, né? Ele ia comigo [...] estava trabalhando 7 dias na semana, de segunda a sexta e sábado e domingo ele me ajudava. Às vezes eram dois markets por dia, era sábado de manhã e sábado à tarde, sexta à noite, domingo. E aí ele falou: "Chega dessa vida, vende só pelo online. [entrevista 17]

Em paralelo, faço cleaner e fico de babá, e meu marido faz Uber e trabalhou um ano no car wash, então assim nós viemos bem da raiz pra ir desenvolvendo e nos estruturando aos poucos, o que tiver pra fazer eu faço, ofereço os doces para as minhas clientes do cleaner, e assim vamos divulgando. [entrevista 18]

O business não ajudou em absolutamente nada. Eu acabei sendo "sponsorado" por um restaurante aqui, fiquei dois anos [...] demorou seis anos pra eu poder sair de outros empregos. Primeiro tem essa limitação de horário de trabalho, então eu não podia estar trabalhando mais de 20 horas então [...] imi- tação de horário de trabalho, e de verba mesmo até o business chegar no break even. [...] Em um ano e meio a gente já estava com o visto de permanente. $\mathrm{O}$ que ajudou foi meu bachelor (degree), [...] acabei fazendo um mestrado em accounting aqui, exatamente quando começamos o business em 2009 [...] isso foi fundamental pro negócio, mas pro visto só o meu bachelor em administração pela Mackenzie [entrevista 21]

\subsection{Adaptação das receitas ao público local}

Com exceção da empresa que faz quentinhas brasileiras, as demais tiveram que adaptar suas receitas para enfocar no público local australiano. Inicialmente muitos empreendedores enfocaram no público brasileiro mas decidiram posteriormente mudar seu foco, conforme relatos:

Eu elaboro o cardápio na semana, mudando toda semana e por enquanto eu só tô com brasileiro. Comida $100 \%$ brasileira, menu até em português. Os clientes são todos brasileiros! Tem colombianos, tem alguns australianos, mas tudo tem "back ground" no Brasil. Já morou no Brasil, gosta da comida. O australiano até come feijoada num sábado, num domingo. Mas não é o foco. Meu projeto agora com as marmitas é ter um selo de informação nutricional. Com isso, posso vender "baldinho de feijoada" em mercados, pois já tenho entrada [entrevista 3]

A gente começou com $90 \%$ de brasileiros e hoje eu acredito que é invertido uns 70\% de australianos e uns 30\% brasileiros. Esse sempre foi o nosso foco. Na época em que pesquisei tinham uns quatro mil brasileiros aqui e a cidade tem dois milhões de habitantes. Então, você nunca pode focar num grupo só. A gente errou muito no começo por sermos brasileiros, fizemos muita coisa que só atraiu o público brasileiro. Então, durante o inverno a gente sofreu muito porque brasileiro quando tá aqui não é um povo que gasta muito dinheiro. Foi quando contratamos um executive chef que faz um trabalho de consultoria pra gente. Como ele é brasileiro, conseguiu manter a nossa identidade nacional, mas reescreveu o menu de uma fôrma que os pratos atraiam o outro público também (australianos). Consultamos três pessoas de marketing, australianos, pra reposicionar a marca. [entrevista 6]

Meus clientes não são brasileiros, na maioria. Pra ser sincero, eu sabia que os brasileiros não iriam sustentar o 'italiano'. [...] O sabor e o paladar do brasileiro são diferentes do australiano. Por exemplo, a gente teve que adaptar todos os meus sites de um jeito vegetariano pra poder atrair australianos. Tivemos que adaptar o pão com alho, que se come na Austrália [...] alguns sabores de frango que a gente come no Brasil [...] o gosto do australiano [...] é um pouco mais apimentado, tem uma linguiça picante que no Brasil a gente também come, [...] outros franguinhos [..] com influência asiática que a gente também não come no Brasil, mas tem que mesclar essa influência toda. O porco com a mostarda e o mel que é uma coisa 
geral, mas também lembra muito o chinês que come aquele porco agridoce $[\ldots]$ tem uma mistura na nossa sobremesa de um pudim de leite condensado que a gente faz, mas todo resto é um mousse de maracujá com brownnie. Então a gente mistura os dois; é um sorvete feito em casa com a receita de pão, a receita do biscoito que é uma receita alemã caseira da minha avó. [entrevista 12]

No nosso primeiro trimestre tivemos muita dificuldade pra entrar, as pessoas não entendiam o que era [...] Daí que a gente viu o nosso nicho, sem a gente perceber tudo que a gente colocou no menu era gluten free, a gente não se tocou disso. Mas aí vc para pra pensar o quanto de comida brasileira é sem glutem [...] a gente nem se ligou porque o nosso era polentinha frita, dadinho de tapioca. As pessoas vinham e falava pra gente vcs que são os gluten free aqui. Nos eventos seguintes a gente nem precisava explicar mais o que era tapioca, o foco era o gluten free. [...] O foco no food truck não é no brasileiro. Se eu fosse depender de brasileiro eu estaria quebrada, não é porque eles não comem, não é que eles achem caro, é que nosso público é formado por pessoas que fazem dietas. $\mathrm{O}$ gluten free, ou o vegano. [entrevista 15]

Eu não divulgo nos grupos do Facebook para os brasileiros. Inicialmente, porque eu sei que brasileiro gosta do tradicional, bolo de brigadeiro, bolo de doce de leite...e eu não tenho para oferecer isso [...] minhas amigas estão me indicando, [...] "Ah, preciso de alguém que faça um bolo lindo, um bolo gostoso [...] os bolos daqui são um pouquinho mais secos, tipo o nosso bolinho com café. $\mathrm{O}$ meu eu diria que é meio termo, a minha massa ela não é nem seca, nem super molhada, [...] Por mais que a pessoa tenha um outro emprego...tem muita gente que tem o business e procura um outro emprego. Mas eu acho que, que... a pessoa quer fazer o que gosta também, né? [...] Todo mundo faz aquilo com prazer, é tão bom pra fazer aquilo, eu acho que é isso. [entrevista 17]

As pessoas ainda têm um preconceito com leite condensado, eles ainda olham como doce por mais que nós tentemos adaptar o sabor pra algo mais leve como chocolate amargo, então pretendemos ampliar e ter uma linha healthy, e também oferecer bolos, tortas, e expandir no geral. $80 \%$ dos clientes são brasileiros. É um público muito bom, mas tenho a visão de que precisamos inovar o negócio. Os brasileiros ativos aqui em Perth são na maioria estudantes, [...] (não) compram um ovo de páscoa que eu vendo a 50 dólares, por exemplo. Meu objetivo é atender todo tipo de público, não só os de classe mais alta. [entrevista 18]

A receita que a minha sogra fez há 10 anos [...] nós utilizamos no início [...] depois, quando já estávamos com a fábrica montada lá em Minas e visitamos umas 10 fábricas. Tivemos até uma consultoria e a receita ela precisou ser modificada porque quando você está no processo caseiro e vai pro processo industrial muda completamente o jeito de você fazer o pão de queijo. [...] na realidade nós tivemos que reduzir um pouco mesmo de sal, pelo paladar local, mas também por questões de health. [...] Desde o início nós participamos do Gluten Free Expo [...] não tem muitas opções gluten free que são gostosas. [...] Até hoje a gente está tentando identificar exatamente a porcentagem entre público Brasileiro e Australiano, e é um desafio (acho) que [...] 90\% do nosso público não é brasileiro até por causa do volume que nós vendemos. Porque hoje em dia você encontra nossos produtos em qualquer canto da Austrália, até na Tasmânia você encontra, são mais de 1500 pontos de venda espalhados pelo (país). [...] Claro que no início foi ao contrário, os brasileiros eram um número muito maior e eles ajudaram bastante a disseminar o produto, através dos vínculos com estrangeiros. Nesses 10 anos o nosso lema foi sempre fazer muitos tastings, e fazer muito evento então nós atingimos 1 milhão de pessoas em WA por ano. Em muitos eventos, roadshows, tastings nos pontos de venda, então ajudou um pouquinho a deixar o produto um pouco mais estabelecido. [Entrevista 21]

\section{FATORES GERADORES DE ALAVANCAGENS ÉTNICAS}

Lembrando que a segunda questão de pesquisa seria identificar quais os fatores geradores de alavancagens étnicas nos negócios de empreendedores imigrantes brasileiros estabelecidos na Austrália Ocidental, evidenciando as características comuns à suas trajetórias empreendedoras, os relatos dos imigrantes iluminaram de forma satisfatória a essas indagações de pesquisa.

As raízes do empreendedorismo étnico podem ser encontradas em uma variedade de fatores estruturais e culturais. Os fatores estruturais se referem ao crescente fluxo de migrantes estrangeiros, restrições econômicas no país anfitrião, acesso insuficiente ao mercado e alto desemprego (LEVENT, MASUREL, Nijkamp, 2003), enquanto o cultural concentra-se em valores específicos, habilidades, relações sociais enraizadas em laços de parentesco ("imersão"), características culturais, incluindo solidariedade e lealdade internas, flexibilidade, motivação pessoal, ética no trabalho, redes dentro do mesmo grupo étnico, acordos de financiamento flexíveis etc. (GRANOVETTER, 1985). De uma perspectiva sintética, o modelo de interação proposto por Aldrich e Waldinger (1990) afirma que estruturas de oportunidades (como condições de mercado, acesso ao empreendedorismo), fatores predisposicionais (como níveis de aspiração, deficiência de linguagem, motivos de migração) e mobilização de fontes (como como redes sociais étnicas, compromisso cultural e religioso) são fatores decisivos para a criação de estratégias empresariais bem-sucedidas (BAYCAN-LEVENT, NIJKAMP, SAHIN, 2009). 
Dessa forma, um elemento importante que influencia diretamente a esfera empreendedora, a saber, os 'tipos de capital' presentes: 'capital econômico', 'capital humano' e 'capital social' (BOURDIEU, 2002).

As habilidades tradicionais adquiridas pelo contato com sua cultura nativa, o entendimento do gosto dos co-étnicos e a adaptação de receitas aos gostos locais foram fundamentais para o sucesso de negócios, sobretudo quando o público consumidor de imigrantes é pequeno. Isto também se verifica quando o produto começa a ganhar escala, como o caso da entrevista 21 (fábrica de pão de queijo). Assim como o que é visto no trabalho de Anthias e Cederberg (2009), a especialização em produtos étnicos demanda não só um senso de pertencimento a sua cultura local, mas enfatiza o bom convívio com outros grupos étnicos, principalmente com o público local. Dessa forma, a criação de tais laços trans-étnicos é composta por elementos funcionais e normativos (necessidade de adaptação ao gosto local, necessidade de fazer o marketing correto para o público local - ver o caso da padaria vegana - entrevista 17), em oposição aos fortes laços solidários desenvolvidos entre brasileiros na localidade.

A etnia ou os elementos culturais podem ser usados como recurso em termos de marketing dos produtos alimentícios, embora nos relatos dos imigrantes brasileiros ocorreu uma busca por "desidentificar" sua herança étnica, e enfatizar características técnicas do produto (vegano, gluten free - entrevistas 17 e 21) ou adaptar receitas para o paladar local (menos sal, mais picante, outros temperos), como sendo os fatores de sucesso mais relevantes.

Enquanto que na pesquisa de Gudmundsson (2013), algumas famílias de sua amostra, dedicadas ao ramo alimentício estão nesse ramo há duas ou mais gerações, havendo transnacionalismo (a migração envolveu a expansão dessas atividades para novos países). Já no caso dos brasileiros na Austrália ocorreu mais um oportunismo derivado de circunstâncias da imigração. No entanto, Gudmundsson (2013) evidencia que na maioria das vezes os imigrantes não estabelecem seus negócios como parte de uma tradição familiar, mas ao contrário, como forma de contornar barreiras linguísticas, culturais ou discriminatórias. Gudmundsson (2013), como imigrantes recém-chegados. Quando a participação da segunda geração nos negócios da família implica em adquirir habilidades, promover sua ambição e estimular sua motivação e um entendimento cultural mais próximo entre as gerações, podemos falar de uma espiral de qualidade de empoderamento e inclusão (GUDMUNDSSON, 2013). No caso da comunidade brasileira na Austrália, por ser recente, ainda não se chegou à segunda geração. Essa segunda geração poderá adquirir habilidades e competências comerciais no manuseio de alimentos e em outros assuntos práticos, que geralmente são transferidos para outras áreas como habilidades gerais e motivação para estudar. Os esforços da primeira geração para se adaptar ao modo de vida no novo país e desenvolver novas habilidades para estabelecer um negócio viável tornam-se muito visíveis para a segunda geração e atribuem grande importância aos pais como modelos. A cooperação entre as gerações nos negócios da família tem um forte elemento de socialização que muitas vezes tem algum efeito positivo na educação da segunda geração. A educação pode ser, portanto, uma maneira de melhorar e expandir os negócios, sendo que as experiências da empresa podem se tornar ativos educacionais que não estão diretamente relacionados ao negócio.

\section{CONSIDERAÇÕES FINAIS}

Retomando o objetivo do artigo, que seria 'contribuir para a compreensão do processo empreendedor de imigrantes que estabelecem negócios de comida, após analisar os casos de empreendedores imigrantes brasileiros no Oeste da Austrália, foram identificadas as características comuns à suas trajetórias empreendedoras, bem como os fatores geradores de alavancagens étnicas nos negócios de empreendedores.

No que diz respeito às características comuns à suas trajetórias empreendedoras, foram identificadas cinco categorias: (i) motivações para empreender, (ii) visto de entrada e trajetórias, (iii) falta de planejamento e entendimento sobre "ter um negócio", (iv) dupla jornada e (v) adaptação das receitas ao público local.

No que diz respeito aos fatores geradores de alavancagens étnicas nos negócios de empreendedores imigrantes brasileiros estabelecidos na Austrália 
Ocidental, foram identificados, fatores estruturais: os empresários passavam por dificuldades econômicas e nem todos tinham bons empregos, e fatores culturais: o brasileiro parece ter uma visão de oportunidades de negócios que o australiano, de maneira geral, não tem. As redes são desenvolvidas tanto no âmbito da comunidade brasileira quanto da australiana e a adaptação de receitas nacionais teve boa aceitação local. Além disso, os relatos demonstraram a tentativa de "desidentificar" sua herança étnica, e enfatizar características técnicas do produto (vegano, gluten free) ou adaptar receitas para o paladar local como fatores de sucesso mais relevantes.

As contribuições teóricas do presente artigo incluem a evidência das trajetórias e características comuns de empreendedores brasileiros no exterior, de um contexto menos pesquisado na Austrália empreendedores brasileiros.

Quanto às implicações práticas, destacam-se: (i) a possibilidade de as histórias descritas no artigo servirem como reflexão a novos imigrantes brasileiros que pretendem abrir negócios, (ii) a possibilidade de se identificarem as características comuns dos negócios, particularmente no que diz respeito às adaptações de receitas e (iii) a necessidade de se realizar um plano de empreendimento como forma de minimizar dificuldades iniciais dos negócios, entre outras.

Destaca-se ainda que em todo o trabalho qualitativo, não cabe generalização dos resultados, portanto como sugestão de trabalhos futuros propõe-se a ampliação da abrangência regional, envolvendo outras cidades da Austrália e a realização de estudo comparativo entre os negócios de alimentos brasileiros em outros países.

\section{REFERÊNCIAS}

ALDRICH, Howard E.; WALDINGER, Roger. Ethnicity and entrepreneurship. Annual review of sociology, v. 16, n. 1, p. 111-135, 1990.

ANTHIAS, Floya. Ethnicity, class, gender, and migration: Greek Cypriots in Britain. Avebury, 1992.
ANTHIAS, Floya; CEDERBERG, Maja. Using ethnic bonds in self-employment and the issue of social capital. Journal of Ethnic and Migration Studies, v. 35, n. 6, p. 901-917, 2009.

APITZCH, U. et al. The chances of the second generation in families of ethnic entrepreneurs: Intergenerational and gender aspects of quality of life processes. 2005.

AUSTRALIAN BUREAU OF STATISTICS - ABS. Australian Census 2016. 2016. Retrieved from: http://www.abs.gov.au/websitedbs/censushome.nsf/ home/CO-56.

Australian Trade and Investment Commission - Austrade. (2019). Education Data - MIP Orbis - Brazil. Retrieved from Commonwealth of Australia: https://www.austrade.gov.au/ Australian/Education/Education-Data/mip-orbis\#/ studentdata? market $=$ BRAZIL

AZMAT, Fara; FUJIMOTO, Yuka. Family embeddedness and entrepreneurship experience: A study of Indian migrant women entrepreneurs in Australia. Entrepreneurship \& Regional Development, v. 28, n. 9-10, p. 630-656, 2016.

BARDIN, Laurence. Análise de conteúdo. 2. tiragem. Lisboa/Portugal: Edições, v. 70, 2006.

BARRETT, Giles A.; JONES, Trevor P.; MCEVOY, David. Ethnic minority business: theoretical discourse in Britain and North America. Urban studies, v. 33, n. 4-5, p. 783-809, 1996.

BASU, Anuradha. An exploration of entrepreneurial activity among Asian small businesses in Britain. Small business economics, v. 10, n. 4, p. 313-326, 1998.

BAYCAN-LEVENT, Tuzin; NIJKAMP, Peter; SAHIN, Mediha. New orientations in ethnic entrepreneurship: motivation, goals and strategies of new generation ethnic entrepreneurs. International journal of foresight and innovation policy, v. 5, n. 1-3, p. 83112, 2009. 
BAZELEY, Patricia; JACKSON, Kristi (Ed.). Qualitative data analysis with NVivo. SAGE publications limited, 2013.

BONACICH, Edna; MODELL, John. The economic basis of ethnic solidarity: Small business in the Japanese American community. Univ of California Press, 1980.

BOUDREAUX, Christopher J. Ethnic diversity and small business venturing. Small Business Economics, v. 54, n. 1, p. 25-41, 2020.

BOURDIEU, P. The Forms of Capital. I NW Biggart. Readings in economic sociology, p. 280-291, 2002.

CECCARELLI, Diego. Native and Immigrant Entrepreneurship. Lessons for Local Liabilities in Globalization from the Prato Case Study. Piccola Impresa/Small Business, n. 3, 2019.

CHOI, Anne Soon. "'La Choy Chinese Food Swings American?:"Korean Immigrant Entrepreneurship and American Orientalism Before World War II. Cultural and Social History, v. 13, n. 4, p. 521-538, 2016.

CLARKE, Connie. Ola Perth - Here comes the Brazilians, PerthNow. 2016. Retrieved from: https://www.perthnow.com.au/lifestyle/stm/olaperth-here-come-the-brazilians-ng-aaab2053e68d$23 \mathrm{ca} 2479882 \mathrm{cf} 2 \mathrm{~b} 70 \mathrm{~b} 41$

COLLINS, Jock. Cultural diversity and entrepreneurship: Policy responses to immigrant entrepreneurs in Australia. Entrepreneurship \& Regional Development, v. 15, n. 2, p. 137-149, 2003.

COLLINS, Jock; LOW, Angeline. Asian female immigrant entrepreneurs in small and medium-sized businesses in Australia. Entrepreneurship and Regional Development, v. 22, n. 1, p. 97-111, 2010.

CRESWELL, John W.; CRESWELL, J. David. Research design: Qualitative, quantitative, and mixed methods approaches. Sage publications, 2017.
CRUZ, Eduardo Picanço; DE QUEIROZFALCÃO, Roberto Pessoa; MANCEBO, Rafael Cuba. Market orientation and strategic decisions on immigrant and ethnic small firms. Journal of International Entrepreneurship, p. 1-29, 2019.

DAHINDEN, Janine. Transnational belonging, non-ethnic forms of identification and diverse mobilities: rethinking migrant integration?. In: Migrations: Interdisciplinary Perspectives. Springer, Vienna, 2012. p. 117-128.

DANA, Leo-Paul; VIRTANEN, Markku; BARNERRASMUSSEN, Wilhelm. Shaking the minority box: Conceptualizing the impact of context and social capital on the entrepreneurial activity of minorities. In: Diaspora Networks in International Business. Springer, Cham, 2019. p. 205-228.

DENZIN, Norman K.; LINCOLN, Yvonna S. (Ed.). The Sage handbook of qualitative research. sage, 2011.

DEPARTMENT OF HOME AFFAIRS - DHA. Student visa and Temporary Graduate visa program report. 2018. Retrieved from Commonwealth of Australia: https://www.homeaffairs.gov.au/ research-and-statistics/statistics/visa-statistics

DION, Delphine; SITZ, Lionel; RÉMY, Eric. Embodied ethnicity: the ethnic affiliation grounded in the body. Consumption Markets \& Culture, v. 14, n. 3, p. 311-331, 2011.

DRORI, Israel; HONIG, Benson; WRIGHT, Mike. Transnational entrepreneurship: An emergent field of study. Entrepreneurship Theory and Practice, v. 33, n. 5, p. 1001-1022, 2009.

EVERTS, Jonathan. Consuming and living the corner shop: belonging, remembering, socialising. Social \& Cultural Geography, v. 11, n. 8, p. 847-863, 2010.

FIRMEZA, George Torquato. Brasileiros no exterior. Fundação Alexandre de Gusmão, 2007. 
FISHER, Greg. Effectuation, causation, and bricolage: A behavioral comparison of emerging theories in entrepreneurship research. Entrepreneurship theory and practice, v. 36, n. 5, p. 1019-1051, 2012.

GIBSON, Margaret A.; OGBU, John U. Minority status and schooling: A comparative study of immigrant and involuntary minorities. Garland Publishing, Inc., 717 Fifth Avenue, Suite 2500, New York, NY 10022, 1991.

GRANOVETTER, Mark. Economic action and social structure: The problem of embeddedness. American journal of sociology, v. 91, n. 3, p. 481-510, 1985.

GUDMUNDSSON, Gestur. Quality spirals and vicious circles among children of immigrant entrepreneurs: How immigrant entrepreneurs' resources are remoulded by the second generation. Young, v. 21, n. 2, p. 173-191, 2013.

HONIG, Benson. Exploring the intersection of transnational, ethnic, and migration entrepreneurship. Journal of Ethnic and Migration Studies, p. 1-17, 2018.

JONES, Trevor; MCEVOY, David; BARRETT, Giles. Labour intensive practices in the ethnic minority firm. Employment, the Small Firm and the Labour Market, London: Routledge, p. 172-205, 1993.

KLOOSTERMAN, Robert; RATH, Jan. Immigrant entrepreneurs in advanced economies: mixed embeddedness further explored. Journal of ethnic and migration studies, v. 27, n. 2, p. 189-201, 2001.

KLOOSTERMAN, Robert C.; RATH, Jan. Mixed embeddedness revisited: A conclusion to the symposium. Sociologica, v. 12, n. 2, p. 103-114, 2018.

LAUGLO, Jon. Working harder to make the grade: Immigrant youth in Norwegian schools. Journal of Youth Studies, v. 2, n. 1, p. 77-100, 1999.
LEVENT, Tüzin Baycan; MASUREL, Enno; NIJKAMP, Peter. Diversity in entrepreneurship: ethnic and female roles in urban economic life. International journal of social economics, 2003.

LEVER-TRACY, Constance; IP, David. Diversification and Extensible Networks: The Strategies of Chinese Businesses in Australia1. International Migration, v. 43, n. 3, p. 73-97, 2005.

LIGHT, Ivan. Immigrant and ethnic enterprise in North America. Ethnic and racial studies, v. 7, n. 2, p. 195-216, 1984.

LIGHT, Ivan; BONACICH, Edna. Immigrant Entrepreneurs: Koreans in Los Angeles, 1965-1982. Univ of California Press, 1988.

MARGOLIS, Maxine L. Goodbye, Brazil: emigrantes brasileiros no mundo. Editora Contexto, 2013.

MARTIN, Nina. Food fight! Immigrant Street Vendors, Gourmet Food Trucks and the Differential Valuation of Creative Producers in C hicago. International Journal of Urban and Regional Research, v. 38, n. 5, p. 1867-1883, 2014.

MORSE, Janice M. Designing funded qualitative research. In Denzin, Norman K. (Ed); Lincoln, Yvonna S. (Ed). (1994). Handbook of qualitative research, (pp. 220-235). Thousand Oaks: Sage Publications, Inc.1994.

PORTES, Alejandro. Social capital: Its origins and applications in modern sociology. Annual review of sociology, v. 24, n. 1, p. 1-24, 1998.

PORTES, Alejandro; SENSENBRENNER, Julia. Embeddedness and immigration: Notes on the social determinants of economic action. American journal of sociology, v. 98, n. 6, p. 1320-1350, 1993.

RAM, Monder. Ethnic minority enterprise: an overview and research agenda. International Journal of Entrepreneurial Behavior \& Research, 1997. 
RAM, Monder et al. Ethnic minority business in comparative perspective: The case of the independent restaurant sector. Journal of Ethnic and Migration Studies, v. 26, n. 3, p. 495-510, 2000.

RAMADANI, Veland et al. Informal ethnic entrepreneurship: An overview. In: Informal ethnic entrepreneurship. Springer, Cham, 2019. p. 1-7.

RAMETSE, Nthati et al. Entrepreneurial Motivations and Capabilities of Migrant Entrepreneurs in Australia. International Migration, v. 56, n. 4, p. 217-234, 2018.

RATH, Jan. (ed.) Immigrant Businesses: The Economic, Political and Social Environment. Basingstoke: Macmillan, 2000.

RATH, Jan; KLOOSTERMAN, Robert. Outsiders' business: a critical review of research on immigrant entrepreneurship. International migration review, v. 34, n. 3, p. 657-681, 2000.

RAY, Krishnendu. Dreams of Pakistani grill and vada pao in Manhattan: Re-inscribing the immigrant body in metropolitan discussions of taste. Food, Culture \& Society, v. 14, n. 2, p. 243-273, 2011.

REZAEI, Shahamak. Breaking out: the dynamics of immigrant owned businesses. Journal of Social Sciences, v. 3, n. 2, p. 94-105, 2007.

RITCHIE, J.; LEWIS, J. Nicholls. CM, \& Ormston, R.(2013). Qualitative research practice: A guide for social science students and researchers.

SARASVATHY, Saras D. Effectuation: Elements of entrepreneurial expertise. Edward Elgar Publishing, 2009.

SHANE, Scott. Reflections on the 2010 AMR decade award: Delivering on the promise of entrepreneurship as a field of research. Academy of Management Review, v. 37, n. 1, p. 10-20, 2012.
SRINIVASAN, Shaila. The South Asian petty bourgeoisie in Britain: an Oxford case study. Avebury, 1995.

WAHLBECK, Östen. Work in the kebab economy: A study of the ethnic economy of Turkish immigrants in Finland. Ethnicities, v. 7, n. 4, p. 543-563, 2007.

WANG, Shuguang; HII, Rebecca. Influence of Immigration Policies on Supply of Ethnic Business Entrepreneurs in Canada. Ryerson Centre for Immigration and Settlement, 2019.

WERBNER, Pnina. Renewing an industrial past: British Pakistani entrepreneurship in Manchester. Migration, n. 8, p. 7-41, 1990.

WILLIAMS, Colin C. The motives of off-the-books entrepreneurs: necessity-or opportunity-driven?. International Entrepreneurship and Management Journal, v. 5, n. 2, p. 203, 2009.

WILSON, Kenneth L.; PORTES, Alejandro. Immigrant enclaves: An analysis of the labor market experiences of Cubans in Miami. American journal of sociology, v. 86, n. 2, p. 295-319, 1980. 